\title{
Long-term results of percutaneous management of malperfusion in acute type $B$ aortic dissection: Implications for thoracic aortic endovascular repair
}

\author{
Himanshu J. Patel, MD, ${ }^{\mathrm{a}}$ David M. Williams, MD, ${ }^{\mathrm{b}}$ Meir Meekov, BA, ${ }^{\mathrm{a}}$ Narasimham L. Dasika, MD, \\ Gilbert R. Upchurch, Jr, MD, ${ }^{\mathrm{a}}$ and G. Michael Deeb, MD ${ }^{\mathrm{a}}$
}

Objective: Open repair for acute type B dissection with malperfusion is associated with significant morbidity. Thoracic aortic endovascular repair has been proposed as a less-invasive therapy for acute type B dissection with malperfusion. Benefits of thoracic aortic endovascular repair include the potential for false lumen thrombosis. Its risks include both early morbidity and mortality, and uncertain late results with potentially unstable landing zones. We present the first long-term analysis of an alternative endovascular approach consisting of percutaneous flap fenestration with true lumen and branch vessel stenting to restore end-organ perfusion.

\begin{abstract}
Methods: Outcomes were analyzed for 69 patients presenting with acute type B dissection with malperfusion from 1997 to 2008. All patients were evaluated with angiography and treated with a combination of flap fenestration, true lumen, or branch vessel stenting where appropriate.
\end{abstract}

Results: Mean age was 57.3 years. Identified malperfused vascular beds included spinal cord (5), mesenteric (40), renal (51), and lower extremity (47). Major morbidity included dialysis need (11), stroke (3), paralysis (2), and 30day mortality $(\mathrm{n}=12,17.4 \%)$. Mean Kaplan-Meier survival was 84.3 months. Although late mortality was associated with age $(P<.0001)$, neither the type nor the number of malperfused vascular beds correlated with vital status at last follow-up $(P>.4)$. Freedom from aortic rupture or open repair at 1,5 , and 8 years was $80.2 \%$, $67.7 \%$, and $54.2 \%$, respectively.

Conclusion: Presentation with acute type B dissection with malperfusion carries a significant risk for both early and late mortality. Percutaneous approaches allow for rapid restoration of end-organ perfusion with acceptable results. These long-term results can serve as comparative data by which to evaluate newer therapies for acute type B dissection with malperfusion, such as thoracic aortic endovascular repair.

In the management of acute type $\mathrm{B}$ dissection (B-AD), operative therapy has assumed a secondary role and is usually reserved for complications arising from the initial insult. ${ }^{1}$ Malperfusion from branch vessel compromise in acute type B dissection (B-MP), a highly morbid complication, results in end-organ dysfunction and limits survival., This indication for operation has been associated with a high risk for major morbidity and mortality. ${ }^{4}$

The role of an endoluminal approach has been growing in response to a perceived need to reduce postoperative morbidity. ${ }^{5-12}$ With the successful application of endograft therapy for thoracic aortic aneurysm repair (TEVAR), several investigators have described its use in B-MP to alleviate end-organ ischemia. ${ }^{8-10}$ Before the reported application of TEVAR for B-MP, we and others described an alternative

From the Departments of Surgery ${ }^{\mathrm{a}}$ and Radiology, ${ }^{\mathrm{b}}$ University of Michigan, Cardiovascular Center, Ann Arbor, Mich.

Read at the Eighty-eighth Annual Meeting of the American Association for Thoracic Surgery, May 10 to 14, 2008, San Diego, California.

Received for publication May 7, 2008; revisions received Nov 11, 2008; accepted for publication Jan 10, 2009; available ahead of print June 17, 2009.

Address for reprints: Himanshu J. Patel, MD, Assistant Professor of Surgery, Section of Cardiac Surgery, 5144 Cardiovascular Center, 1500 E. Medical Center Drive SPC 5864, Ann Arbor, MI 48109-586 (E-mail: hjpatel@med.umich.edu).

J Thorac Cardiovasc Surg 2009;138:300-8

$0022-5223 / \$ 36.00$

Copyright (c) 2009 by The American Association for Thoracic Surgery doi: $10.1016 /$ j.jtcvs.2009.01.037 approach to relieve end-organ ischemia without the need for open aortic resection or fenestration, to avoid the reportedly high rates of morbidity and mortality with these procedures. In this percutaneous technique, the dissection flap is fenestrated, and the aortic true lumen is then stented open to prevent dynamic collapse onto the origin of the branch vessel. ${ }^{6,7}$ Branch vessel stenting is then performed for associated continued static obstruction. The purpose of the current report is to describe the long-term outcomes of this endovascular approach in the treatment of malperfusion in $\mathrm{B}-\mathrm{AD}$ and provide objective data so that suitable comparative analyses may be conducted for newer therapies, such as TEVAR.

\section{MATERIALS AND METHODS}

This study was approved by the institutional review board of the University of Michigan Hospitals (institutional review board study 2003-0128). Informed consent requirements were waived for this study.

Data from all patients admitted to the University of Michigan Hospitals between 1997 and 2008 with a diagnosis of B-MP were prospectively collected and retrospectively analyzed. B-AD for this study was defined as its occurrence within 14 days of presentation to the hospital and with pathology confined to the thoracoabdominal aorta distal to the left subclavian artery. Diagnosis of B-AD was made by the combination of clinical factors, including history and physical examination, and either the use of dynamic computed tomography (CT) or transesophageal echocardiography. A combination of clinic and hospital records, imaging studies, and query of the 


\section{Abbreviations and Acronyms \\ $\mathrm{B}-\mathrm{AD}=$ acute type $\mathrm{B}$ dissection \\ $\mathrm{B}-\mathrm{MP}=$ acute type $\mathrm{B}$ dissection with malperfusion \\ CT = computed tomography}

TEVAR $=$ thoracic aortic aneurysm repair

National Death Index was used to obtain in-hospital and long-term information. Follow-up was $100 \%$ complete at a mean of 41.9 months (median 37.4 months).

The primary therapy for B-AD at the University of Michigan is medical therapy to reduce cardiac contractile force and blood pressure management to maintain systolic blood pressure less than $120 \mathrm{~mm} \mathrm{Hg}$. Patients who presented with evidence of end-organ ischemia (ie, abdominal pain or tenderness, lactic acidosis, hyperamylasemia, abnormal transaminases, elevated creatinine or reduced urine output, pulse deficit with or without sensorimotor changes, or evidence of paraplegia) proceeded to angiography. Those patients who also had evidence of complete true lumen collapse or CT evidence of bowel or renal malperfusion without clinical evidence of endorgan dysfunction were also sent for angiography. An aggressive stance was deemed appropriate in this latter group to avoid the delay from onset of known angiographic malperfusion to clinical sequelae. In the application of these criteria, 105 patients underwent angiography to evaluate for B-MP. After excluding those patients without angiographic evidence of branch vessel compromise, as well as those in whom angiography was undertaken after open aortic repair, a subset of 69 patients was identified as the target cohort for analysis. This group completed diagnostic angiography and intervention at a median of 1 day after presentation. Clinical evidence of malperfusion was suspected in all but 2 patients who underwent study predominantly for radiographic findings. Marked true lumen collapse (new finding) was identified in both patients on standard follow-up CT scans obtained at 1 week after initial presentation, and this prompted referral for angiography.

The angiographic evaluation for malperfusion is entirely a percutaneous method and has been described in detail. ${ }^{6,13}$ When branch vessel obstruction is present, the first priority is to reperfuse the mesenteric vessels first, followed by renal and limb revascularization. When dynamic obstruction of the branch vessels is present, flap fenestration to create a large reentry tear is performed. Although fenestration can equalize pressures across the dissection flap, self-expanding 16- to 22-mm diameter Wallstents (Schneider, Minneapolis MN) are usually placed to buttress open the aortic true lumen and are typically placed near the compromised branch vessel. Fenestration and stenting of the aortic true lumen treat the dynamic obstruction of branch vessels but not the static obstruction if also present. The latter is determined by identifying a significant $(\geq 20 \mathrm{~mm} \mathrm{Hg})$ systolic gradient from the aorta to the branch vessel. The true lumen of the artery that is compromised by a static obstruction is cannulated and treated with a self-expanding stent to relieve the obstruction. Completion manometry confirms adequate perfusion. It is important to note that the procedure is primarily based on the use of intravascular ultrasound and manometry and that dye load is minimized to prevent renal injury (usually $<50 \mathrm{~mL}$ ). This is primarily accomplished by using hand injections of contrast material for confirmation of catheter placement in branch vessels to obtain manometric measurements and avoidance of high-volume aortography.

Postoperative management after intervention in all patients consisted of aspirin therapy and standard management of blood pressure and end-organ dysfunction. When spinal cord ischemia was present, cerebrospinal fluid drainage was instituted before angiographic study and maintained for at least 48 hours after the procedure. All patients were then imaged before discharge from the hospital to evaluate the aorta. Standard imaging protocols for follow-up after discharge include obtaining CT scans at 1 month,
3 months, and annually thereafter. Indications for aortic repair during the chronic phase include 1) presence of symptoms; 2) presence of a re-dissection, or 3) growth rate of more than $1 \mathrm{~cm} / \mathrm{y}$, or an absolute diameter greater than 5.5 to $6 \mathrm{~cm}$ in asymptomatic patients. Our imaging follow-up was incomplete with 15 patients $(21 \%)$ receiving no imaging after discharge.

\section{Statistical Analysis}

Early outcomes included rates of mortality, stroke, renal failure needing dialysis, and spinal cord ischemia. The primary late outcomes of interest were vital status with survival time. Early mortality was defined as that occurring within 30 days of admission or in-hospital death. Late mortality was defined as that occurring thereafter.

Data were analyzed using the Statistical Package for the Social Sciences (SPSS Inc., Chicago IL). All data are expressed as mean \pm standard deviation where applicable. Dichotomous variables were evaluated using chi-square analysis, and continuous variables were evaluated using 1-way analysis of variance. Multivariate models (binary logistic regression) were constructed using a backward conditional process to identify factors that were independently associated with each of the outcomes of interest. The factors used in multivariate analysis included using those with $P \leq .1$ significance on univariate analysis. Survival analysis was analyzed by Kaplan-Meier methods.

\section{RESULTS}

Sixty-nine patients were found to have evidence of malperfusion on angiography. Demographics and comorbidities of this group are listed in Table 1. The patterns of malperfusion in this cohort are also listed in Table 1 and include both clinical presentation findings and those obtained on angiography. The majority of patients had involvement of multiple beds on angiography $(69.6 \%)$. The distribution of involved arterial beds is also listed in Table 1. There were 3 treatment options in the cohort. The therapy in all patients involved various combinations of these 3 options based on the findings on arteriography (Figure 1, Table 1). This resulted in complete angiographic reperfusion in all patients except 5 . Two of these patients had spinal cord symptoms only and presented with a thrombosed false lumen. One patient had cord ischemia and a transceliac artery gradient of $43 \mathrm{~mm}$ $\mathrm{Hg}$ and was not treated because of a large patent superior mesenteric artery supplying hepatic flow. The remaining 2 patients had renal malperfusion, and technical issues prevented successful therapy.

When accounting for 185 malperfused vascular beds (identifying each kidney and limb as separate beds), the overall technical success rate for flow restoration was $95.7 \%$. In 5 patients who all had renal malperfusion, technical issues prevented placement of branch stents. Another patient with right renal and mesenteric malperfusion had intramural hematoma causing a gradient in the kidney. This was left untreated because his overall clinical condition required prolonged efforts to restore mesenteric perfusion with mechanical thrombolysis and flap fenestration. On a follow-up CT scan, the renal artery intramural hematoma had resolved. One patient who presented with malperfusion of his right kidney, superior mesenteric artery, and both limbs was noted to have a thrombosed infrarenal aortoiliac graft. Visceral and renal perfusion were restored with fenestration. 
TABLE 1. Demographics, comorbidities, and presentation patterns

\begin{tabular}{|c|c|}
\hline Variable & Frequency $(n=69)$ \\
\hline \multicolumn{2}{|l|}{ Demographics } \\
\hline Mean age $(y)$ & $57.3 \pm 12.1$ \\
\hline Male sex & $54(78.2 \%)$ \\
\hline Coronary artery disease & $9(13.0 \%)$ \\
\hline Myocardial infarction & $6(8.7 \%)$ \\
\hline Hypertension & $57(82.6 \%)$ \\
\hline Diabetes mellitus & $9(13.0 \%)$ \\
\hline Chronic obstructive pulmonary disease & $11(15.9 \%)$ \\
\hline Peripheral vascular disease & $10(14.5 \%)$ \\
\hline Stroke & $6(8.7 \%)$ \\
\hline Renal insufficiency & $5(7.2 \%)$ \\
\hline Creatinine on admission (mg/dL) & $1.7 \pm 1.1$ \\
\hline Marfan syndrome & $3(4.3 \%)$ \\
\hline Clinical findings of malperfusion* & No. affected* \\
\hline Spinal cord ischemia & 5 \\
\hline \multicolumn{2}{|l|}{ Mesenteric malperfusion } \\
\hline Acute abdomen & 5 \\
\hline Hematochezia or hematemesis & 2 \\
\hline $\begin{array}{l}\text { Acidosis, elevated transaminases, amylase, or } \\
\text { lipase }\end{array}$ & 6 \\
\hline Severe abdominal pain, nausea, or vomiting & 10 \\
\hline \multicolumn{2}{|l|}{ Renal malperfusion } \\
\hline Elevated creatinine & 19 \\
\hline Oliguria/anuria & 5 \\
\hline Refractory hypertension & 6 \\
\hline \multicolumn{2}{|l|}{ Limb malperfusion } \\
\hline Loss of pulses or sensorimotor changes & 26 \\
\hline Angiographic findings & No. affected \\
\hline \multicolumn{2}{|l|}{ Affected vascular beds on angiography } \\
\hline Spinal cord & $5(7.2 \%)$ \\
\hline Mesenteric & $40(58.0 \%)$ \\
\hline Renal & $51(73.9 \%)$ \\
\hline Limb & $47(68.1 \%)$ \\
\hline \multicolumn{2}{|l|}{ No. of affected vascular beds on angiography } \\
\hline 1 & $21(30.4 \%)$ \\
\hline 2 & $23(33.3 \%)$ \\
\hline 3 & $25(36.2 \%)$ \\
\hline \multicolumn{2}{|l|}{ Type of percutaneous intervention } \\
\hline Flap fenestration alone & 4 \\
\hline Flap fenestration and true lumen stenting & 16 \\
\hline $\begin{array}{l}\text { Flap fenestration, true lumen, and branch vessel } \\
\text { stenting }\end{array}$ & 23 \\
\hline Flap fenestration and branch vessel stenting & 5 \\
\hline True lumen and branch vessel stenting & 3 \\
\hline Branch vessel stenting alone & 13 \\
\hline
\end{tabular}

*More than 1 may be present per patient.

Flow was restored percutaneously in 1 limb with mechanical thrombolysis before performance of a femoral-femoral crossover graft and fasciotomies. Finally, in 1 patient, the celiac artery was not treated for reasons noted above.

\section{Early Results}

The median length of stay was 11 days. Early mortality was seen in 12 patients $(17.4 \%)$. By univariate analysis, only increased age correlated with early mortality (mean age of 55.5 years for survivors vs 65.8 years for expired patients, $P=.006$ ). Correlative trends were seen in those presenting with a history of peripheral vascular disease $(P=.067)$ and those who required dialysis $(P=.07)$. Neither the number nor the type of malperfused vascular beds correlated with early mortality (all $P \geq .5$ ). The causes of early mortality and the corresponding clinical scenarios are listed in Table 2. Aortic rupture was the identified cause of death in 5 patients. Although the site of fenestration in all patients was intraabdominal, and the site of rupture in all was intrathoracic, the procedure cannot be excluded as a contributing factor for rupture. Finally, there were no instances of retrograde type A dissection related to the procedure.

Major morbidity included stroke, which occurred in 3 patients $(4.3 \%)$. Two patients who presented with poorly controlled hypertension sustained strokes in watershed regions likely secondary to overly aggressive antihypertensive therapy. The remaining patient had a procedurally related event and an expressive aphasia with near complete resolution 1 month after discharge. Dialysis was required in 10 patients $(14.5 \%)$, and renal function recovered in all but 3 who died of multisystem organ failure related to their malperfusion syndrome. Finally, the incidence of permanent spinal cord ischemia in this cohort was $2.9 \%(n=2$ patients). Both of these patients presented initially with paraplegia from their acute dissection.

To generate a sufficient event rate for analysis, a composite end point of adverse events was constructed to include in-hospital or 30-day mortality, need for dialysis, and occurrence of stroke or spinal cord ischemia. Univariate binary variables correlating with this end point included a history of peripheral vascular disease $(P=.05)$ or renal insufficiency $(P=.02)$, the occurrence of limb malperfusion $(P=.02)$, or the presence of 3 or more malperfused vascular beds $(P=.05)$. The only continuous variable correlating with occurrence of composite outcome was an elevated admission creatinine $(2.3 \pm 1.4$ vs no occurrence of composite outcome $1.3 \pm 0.6, P<.0001)$. The only predictive variables of a poor outcome on multivariate analysis were the presence of peripheral vascular disease $(P=.028)$, an elevated admission creatinine $(P=.005)$, and the presence of limb malperfusion $(P=.015)$.

\section{Late Results}

In this cohort, the overall crude all-cause mortality rate at last follow-up was $36.2 \%(n=25)$. The actuarial survival curve is shown in Figure 2, identifying a mean survival of 84.3 months. By univariate analysis, only increased age correlated with late mortality (mean age of 53.4 years for survivors vs 64.4 years for expired patients, $P<.0001)$. By Kaplan-Meier analysis, there were no time-dependent effects of different malperfused beds on late survival (all beds $P>.5$ ). Fourteen patients sustained aortic rupture 

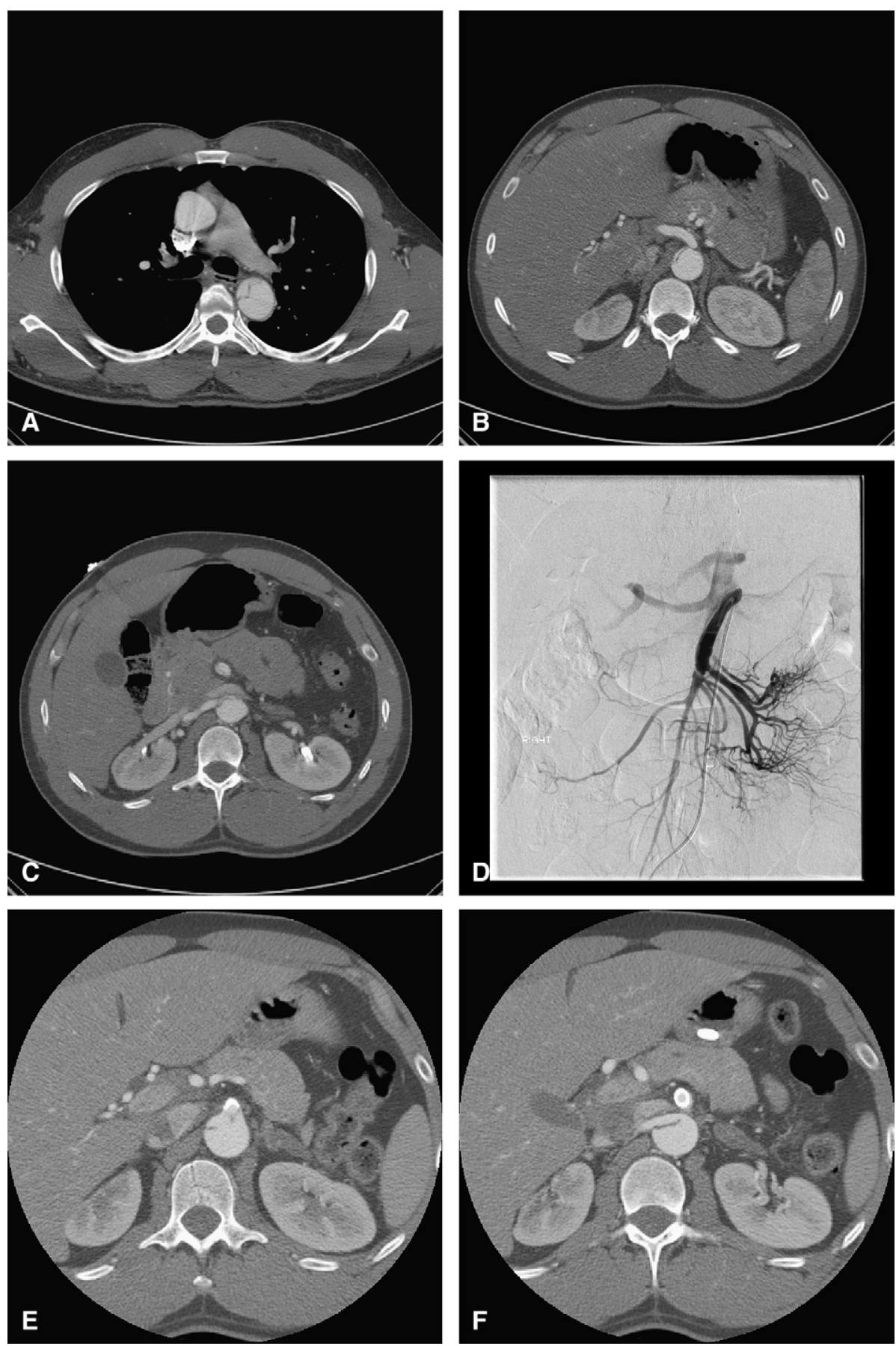

FIGURE 1. Endovascular management of visceral ischemia. This 40 -year-old man presented initially with severe neck, chest, and back pain. He was seen at an outside institution and transferred after a diagnosis of B-AD. After transfer, he was noted to have mild abdominal discomfort. CT scan suggested near total aortic true lumen collapse in the proximal descending aorta (A), with suggestion of a dynamically compromised celiac artery origin (B), and a collapsed true lumen and dissection flap within the superior mesenteric artery (SMA), suggesting both dynamic and static obstruction of this vessel (C). On angiographic evaluation, he was found to have a dissection flap extending into the SMA with an aorto-mesenteric gradient of $43 \mathrm{~mm} \mathrm{Hg}$ (D). He was also noted on intravascular ultrasound to have dynamic compromise of the celiac, superior mesenteric, and right renal artery origins. He underwent aortoplasty (fenestration) and true lumen stenting at the level of the celiac artery, which resolved all gradients except that seen in his SMA. He subsequently underwent placement of a stent into the SMA branch directly with complete resolution of the aorto-mesenteric gradient. Follow-up imaging at 1 month shows a patent fenestration tear in the dissection flap (E) and a patent stent in the SMA itself (F). 
TABLE 2. Causes of early mortality

\begin{tabular}{|c|c|c|c|c|}
\hline $\begin{array}{l}\text { Patient } \\
\text { age }(y)\end{array}$ & Presenting symptoms & $\begin{array}{c}\text { Affected } \\
\text { vascular beds }\end{array}$ & Intervention & Cause of mortality \\
\hline 51 & $\begin{array}{l}\text { Lower-extremity } \\
\text { sensorimotor changes }\end{array}$ & $\begin{array}{l}\text { Renal, mesenteric, } \\
\quad \text { limb }\end{array}$ & $\begin{array}{l}\text { Fenestration, true lumen stenting, SMA angioplasty, } \\
\text { thrombolysis of prior infrarenal aortic tube graft }\end{array}$ & Multisystem organ failure* \\
\hline 56 & $\begin{array}{l}\text { Limb ischemia, } \\
\text { progressive acidosis }\end{array}$ & Mesenteric, limb & Fenestration, true lumen stenting & Multisystem organ failure \\
\hline 53 & Acute abdomen & Renal, mesenteric & $\begin{array}{l}\text { Stenting of SMA, celiac axis, left renal, and aortoiliac } \\
\text { vessels }\end{array}$ & Multisystem organ failure* \\
\hline 51 & Acute abdomen & $\begin{array}{l}\text { Renal, mesenteric, } \\
\quad \operatorname{limb}\end{array}$ & $\begin{array}{l}\text { Fenestration, true lumen stenting, SMA, celiac and left } \\
\text { renal arterial stenting }\end{array}$ & Multisystem organ failure \\
\hline 61 & Acute abdomen & Renal, mesenteric & Fenestration, SMA and celiac axis stenting & $\begin{array}{l}\text { Watershed infarct in patient } \\
\text { with history of multiple strokes* }\end{array}$ \\
\hline 71 & $\begin{array}{l}\text { Limb sensorimotor } \\
\text { changes }\end{array}$ & Limb & Fenestration & $\begin{array}{l}\text { False lumen rupture on } \\
\text { post-procedure day } 2\end{array}$ \\
\hline 76 & $\begin{array}{l}\text { Limb sensorimotor } \\
\text { changes }\end{array}$ & Renal, limb & Fenestration, aortoiliac stenting & $\begin{array}{l}\text { False lumen rupture on } \\
\text { post-procedure day } 4\end{array}$ \\
\hline 74 & Elevated creatinine & Renal, limb & $\begin{array}{l}\text { Fenestration, aortoiliac stenting, renal artery stenting, } \\
\text { and suction embolectomy }\end{array}$ & $\begin{array}{l}\text { False lumen rupture on } \\
\text { post-procedure day } 7\end{array}$ \\
\hline 67 & $\begin{array}{l}\text { Acidosis, cadaveric limbs, } \\
\text { obtundation }\end{array}$ & $\begin{array}{l}\text { Renal, mesenteric, } \\
\text { limb }\end{array}$ & Fenestration, aortoiliac and SMA stenting & Multisystem organ failure \\
\hline 85 & $\begin{array}{l}\text { Noted extension of } \\
\text { dissection on } \\
\text { follow-up imaging }\end{array}$ & Renal & Fenestration, renal artery stenting & $\begin{array}{l}\text { False lumen rupture on } \\
\text { post-procedure day } 2\end{array}$ \\
\hline 71 & $\begin{array}{l}\text { Infrarenal aortic thrombosis, } \\
\text { cadaveric legs }\end{array}$ & $\begin{array}{l}\text { Renal, mesenteric, } \\
\text { limb }\end{array}$ & True lumen stenting & $\begin{array}{l}\text { Multiorgan failure after } \\
\text { recurrent aortic thrombosis }\end{array}$ \\
\hline 74 & Cadaveric limbs & $\begin{array}{l}\text { Renal, mesenteric, } \\
\quad \operatorname{limb}\end{array}$ & $\begin{array}{l}\text { Fenestration, true lumen stenting, mechanical } \\
\text { thrombolysis of prior aortoiliac graft }\end{array}$ & $\begin{array}{l}\text { False lumen rupture on } \\
\text { post-procedure day } 5\end{array}$ \\
\hline
\end{tabular}

$(\mathrm{n}=5$, all in-hospital) or need for aortic resection $(\mathrm{n}=9)$ during follow-up. Kaplan-Meier analysis of freedom from aortic rupture or need for aortic repair is shown in Figure 3. This demonstrates a mean time to rupture or need for repair of 79.2 months.

\section{DISCUSSION}

The pathophysiology of malperfusion in B-AD consists principally of both dynamic and static obstruction of the involved branch vessel. ${ }^{6,13}$ In static obstruction, the dissection flap enters the branch vessel with absent or inadequate distal reentry and causes ischemia by reducing the true lumen diameter. In contrast, the dissection flap in dynamic obstruction intermittently prolapses across the orifice of the branch vessel during the cardiac cycle, and this subsequently results in end-organ ischemia. In addition to traditional clinical criteria demonstrating evidence of endorgan ischemia, the diagnosis of malperfusion also rests on the manometric or angiographic demonstration of ongoing anatomic branch artery obstruction. It should be noted that the clinical diagnosis of malperfusion, based for example on newly diagnosed renal insufficiency, cannot distinguish acute renal injury caused by transient but resolved renal artery obstruction from that caused by ongoing mechanical obstruction.
Recent studies have suggested that B-AD carries an inhospital mortality rate of $10 \%$ to $15 \%{ }^{1,2}$ The International Registry of Acute Dissection consortium identified the presence of branch vessel compromise as an important

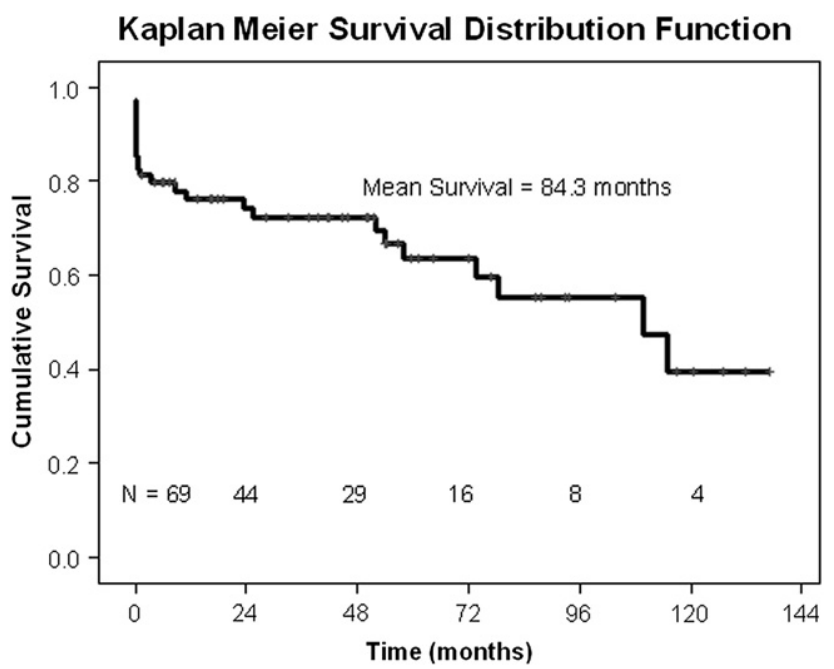

FIGURE 2. Kaplan-Meier analysis of survival after presentation with B-MP. This figure demonstrates that patients presenting with B-AD have a dismal prognosis with 1-, 5-, and 8-year survivals of $76.2 \%, 63.5 \%$, and $55.3 \%$, respectively. The overall mortality rate in this entire cohort was $36.2 \%$ at a mean follow-up of 41.9 months. 


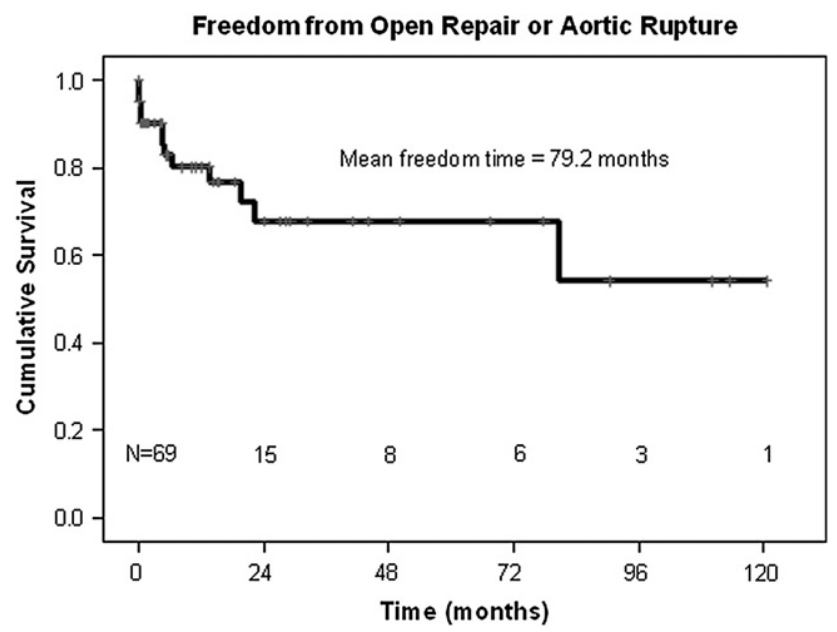

FIGURE 3. Actuarial freedom from aortic repair or rupture. This KaplanMeier analysis suggests that the 1-, 5-, and 8-year freedoms from operative repair or aortic rupture are $80.2 \%, 67.7 \%$, and $54.2 \%$, respectively.

independent determinant of early mortality. ${ }^{2}$ Classic therapy in the setting of malperfusion consists of open repair of the aorta by resection of the primary entry tear, direct bypass grafting of the involved branch vessels, or creation of a fenestration in the abdominal aorta. ${ }^{1,3-5}$ However, results with operative therapy for B-AD have been dismal, with early mortality rates approaching $40 \% \cdot{ }^{1-5,14}$

It was in this setting that we and others described an endovascular solution to relieve end-organ ischemia from branch vessel compromise as a possible means to improve early outcomes. ${ }^{6,7}$ In this approach, dynamic obstruction is relieved by percutaneously creating a flap fenestration to generate a large reentry tear. The true lumen is then stented open in the region of the involved branch to alleviate the dynamic obstruction. For static obstruction, the endovascular approach consists of placement of stents into the target vessel.

Thoracic endografting has been proposed as an alternative solution to open repair or percutaneous fenestration as a means to resolve B-AD. ${ }^{8-12,15}$ With this approach, the entry tear is sealed by TEVAR, and the dynamic obstruction is then relieved. Associated static obstruction is not treated by TEVAR and requires open revascularization or branch vessel stenting. Benefits of TEVAR in this setting include promoting thrombosis of the false lumen with subsequent beneficial aortic remodeling. ${ }^{15}$ This would be of significant benefit in alleviating the inherently increased risk for rupture present in those patients presenting with an acute dissection with ectatic or frankly aneurysmal aortic dimensions. ${ }^{16}$ The demonstration of beneficial aortic remodeling after TEVAR for B-AD was first defined in landmark studies by Dake and colleagues. ${ }^{8}$ Although early results of TEVAR have suggested efficacy, no study to date describes the long-term outcomes with this approach on aortic growth rates. Szeto and colleagues,${ }^{17}$ from the University of Pennsylvania, de- scribed the use of TEVAR for B-MP in 17 patients. They reported a $0 \%$ operative mortality and a $94 \% 1$-year survival. However, long-term data in that study were lacking, and the incidence of neurologic complications in the entire series of complicated type B dissection $(\mathrm{n}=35)$ exceeded $10 \%$. In another recent intermediate-term analysis, complete thrombosis of the false lumen was achieved in only $64.7 \%$ of acute type IIIb dissections. ${ }^{11}$ An additional theoretic concern for long-term success with the use of TEVAR for B-AD is that the landing zone(s) may be unstable if they exist in dissected aorta. Sizing the aorta for correct endograft selection can also be problematic, particularly in the distal portion of the repair, because the dissected aorta will continue to remodel. A rare but often malignant complication of TEVAR in $\mathrm{B}-\mathrm{AD}$ is the occurrence in $2 \%$ to $4 \%$ of patients of a retrograde dissection into the ascending aorta with its catastrophic sequelae. ${ }^{12,15}$ This lethal complication was not seen in our series of percutaneous fenestration. Finally, in performing TEVAR, there is a concern for spinal cord ischemia with intercostal artery coverage, particularly if the left subclavian artery requires exclusion. ${ }^{8-12,15}$ This latter concern is eliminated with percutaneous fenestration techniques, because there is no inherent loss of intercostal arteries in contrast with TEVAR. Indeed, given the high rates of neurologic morbidity seen with TEVAR for acute dissection, this may be a most important advantage of percutaneous fenestration over TEVAR. ${ }^{17}$

The current study describes late outcomes for one of the largest cohorts of $\mathrm{B}-\mathrm{AD}$ presenting with malperfusion syndrome. The early mortality seen in our series suggests that the fenestration procedure has significantly reduced early mortality when compared with open surgery and is similar to that reported in other series of uncomplicated type B dissection. ${ }^{2}$ However, the major weakness of a percutaneous fenestration approach extends from its inability to allow for favorable aortic remodeling after the procedure. By creating a large reentry tear, flow is ensured within the false lumen, thus precluding its thrombosis. In essence, what is created by the percutaneous fenestration approach is an anatomic conversion from a complicated dissection to an uncomplicated one, whereby the branch vessel compromise and not the aorta per se is treated. This allows for the patient to recover from the effects of the malperfusion syndrome without the associated morbidity of an open aortic repair in this setting. Presumably, however, if an indication for aortic repair exists on the basis of aortic dimension, it can then be done in a more elective and controlled fashion after resolution of the malperfusion syndrome. An important limitation of this approach (in contrast with open surgery or TEVAR) is its inability to treat the risk for aortic rupture. In our series, 5 patients $(7.2 \%)$ sustained aortic rupture. Although the site for fenestration was intraabdominal, and the site of rupture in all was thoracic, it is possible that hemodynamic alterations after fenestration contributed to rupture. 
A TEVAR approach in this situation may have eliminated the risk for rupture. It is unclear, however, whether this benefit of TEVAR outweighs its reported risk of paraplegia or retrograde dissection, neither of which was observed with the percutaneous fenestration approach in our series.

\section{Study Limitations}

Limitations of this study include its retrospective nature and lack of comparison group (eg, open repair, TEVAR, or open fenestration groups). In addition, although this study describes outcomes for treatment of one of the largest series of patients with B-MP, the sample size is relatively small. Finally, although the follow-up for the primary end point of mortality is complete, there is incomplete imaging followup ( $21 \%$ without postdischarge imaging).

Our current approach at the University of Michigan is based on risk stratification to determine the most suitable option. We elect to perform fenestration and stenting for those patients with small total aortic diameters presenting with malperfusion. If the patient is young but presents with an aortic diameter greater than $5 \mathrm{~cm}$, we will initially attempt to resolve the malperfusion with fenestration and stenting and then subsequently treat the aneurysm with an open approach within several weeks of presentation. TEVAR is reserved for those presenting with malperfusion who are older ( $\geq 70$ years) and have total aortic diameters greater than 4.5 to $5 \mathrm{~cm}$ or those presenting with the complication of rupture in association with malperfusion.

\section{CONCLUSIONS}

We have described the late results of a percutaneousbased approach for the treatment of peripheral ischemic complications resulting from B-AD. In contrast with data reported from open repair, these long-term data may serve as a more suitable comparison against which to evaluate TEVAR as a primary therapeutic modality for this lethal disease.

\section{References}

1. Elefteriades JA, Lovoulos CJ, Coady MA, Tellides G, Kopf GS, Rizzo JA. Management of descending aortic dissection. Ann Thorac Surg. 1999;67:2002-5.

2. Suzuki Y, Mehta RH, Ince H, Nagai R, Sakomura Y, Weber F, et al. Clinical profiles and outcomes of acute type B aortic dissection in the current era: lessons from the International Registry of Aortic Dissection. Circulation. 2003;108:II312-7.

3. Lauterbach SR, Cambria RP, Brewster DC, Gertler JP, Lamuraglia GM, Isselbacher EM, et al. Contemporary management of aortic branch compromise resulting from acute aortic dissection. J Vasc Surg. 2001;33:1185-92.

4. Fann JI, Sarris GE, Mitchell RS, Shumway NE, Stinson EB, Oyer PE, et al. Treatment of patients with aortic dissection presenting with peripheral vascular complications. Ann Surg. 1990;212:705-13.

5. Trimarchi S, Nienaber CA, Rampoldi V, Myrmel T, Suzuki T, Bossone E, et al. Role and results of surgery in acute type B aortic dissection: insights from the International Registry of Acute Aortic Dissection. Circulation. 206;114:I357-64.

6. Williams DM, Lee DY, Hamilton BH, Marx MV, Narasimham DL, Kazanjian SN, et al. The dissected aorta: percutaneous treatment of ischemic complications-principles and results. J Vasc Interv Radiol. 1997;8:605-25.

7. Slonim SM, Miller DC, Mitchell RS, Semba CP, Razavi MK, Dake MD. Percutaneous balloon fenestration and stenting for life-threatening ischemic complica- tions in patients with acute aortic dissection. J Thorac Cardiovasc Surg. 1999; 117:1118-27.

8. Dake MD, Kato N, Mitchell RS, Semba CP, Razavi MK, Shimono T, et al. Endovascular stent-graft placement for treatment of acute aortic dissection. $N$ Engl J Med. 1999;340:1546-52.

9. Nienaber CA, Fattori R, Lund G, Dieckmann C, Wolf W, von Kodolitsch Y, et al. Nonsurgical reconstruction of thoracic aortic dissection by stent-graft placement. N Engl J Med. 1999;340:1539-45.

10. Eskandari MK, Peterson BG. Endovascular repair of descending aortic dissections. Semin Thorac Cardiovasc Surg. 2005; 17:268-73.

11. Rodriguez JA, Olsen DM, Lucas L, Wheatley G, Ramaiah V, Diethrich EB. Aortic remodeling after endografting of thoracoabdominal aortic dissection. J Vasc Surg. 2008;47:1066-70.

12. Hansen CJ, Bui H, Donayre CE, Aziz I, Kim B, Walot I, et al. Complications of endovascular repair of high risk and emergent descending thoracic aortic aneurysms and dissections. J Vasc Surg. 2004;40:228-34.

13. Patel HJ, Williams DM. Endovascular therapy for malperfusion in acute type B aortic dissection. Op Tech Thorac Cardiovasc Surg. 2009:14:2-11.

14. Panneton JM, The SH, Cherry KJ Jr, Hofer JM, Glovickzi P, Andrews JC, et al. Aortic fenestration for acute or chronic aortic dissection: an uncommon but effective procedure. J Vasc Surg. 2000;32:711-21.

15. Swee W, Dake MD. Endovascular management of thoracic dissections. Circulation. 2008;117:1460-73.

16. Kato M, Bai H, Sato K, Kawamoto S, Kaneko M, Ueda T, et al. Determining surgical indications for acute type $\mathrm{B}$ dissection based on enlargement of aortic diameter during the chronic phase. Circulation. 1995;92:II107-12.

17. Szeto WY, McGarvey M, Pochettino A, Moser GW, Hoboken A, Cornelius K, et al. Results of a new surgical paradigm: endovascular repair for acute complicated type B dissection. Ann Thorac Surg. 2008;86:87-94.

\section{Discussion}

Eric Roselli, MD (Cleveland, Ohio). Congratulations on a fine presentation and an outstanding experience. Dr Patel and I did some of our endovascular training together under the leadership of Roy Greenberg, who apologizes for not being here today, but he and I reviewed the article together and compiled the following questions and observations.

Dr Patel and colleagues at the University of Michigan have provided us with a relatively large amount of long-term data regarding a technique used to treat malperfusion syndrome after acute distal dissection. Dr Williams and his counterparts have long been considered the pioneers of these complex interventional techniques, and their expertise in aortic flap fenestrations is likely unparalleled. However, several fundamental questions are raised by both the implementation of such a treatment strategy and the extended followup data you have provided.

Would you please clarify your patient population? Malperfusion is really a clinical syndrome rather than a radiographic diagnosis, yet in your series you included patients with a clinical syndrome and evidence of true lumen collapse by computed axial tomography scan. Can you segregate your results to provide us with the number of patients treated solely on the basis of radiographic evidence of true lumen collapse or ischemia versus those with clinical evidence of this complication along with their respective outcomes?

Dr Patel. You are absolutely correct in that there is a difference between radiographic findings and presentation with a syndrome of end-organ dysfunction. We completely agree with that. The latter, the syndrome of end-organ dysfunction, results from prolonged ischemia, and at our center, because of the availability of these interventional techniques, we have taken an aggressive stance in studying patients who present with angiographic or CT findings to prevent the subsequent development of end-organ failure from prolonged ischemia. 
We did perform the analysis that you suggested and found no statistical difference in outcomes, and this was likely secondary to the small sample size in the group that was studied only for angiographic findings.

Dr Roselli. Very good. The 2 therapies principally used to treat malperfusion after acute aortic dissection remain endovascular grafting and aortic flap fenestration, as you clearly described to us in the beginning of your talk. We have used both techniques; however, the pendulum has recently swung strongly in the direction of stent-graft therapy. Although some of this may relate to the relative simplicity of endovascular grafting over the flap fenestration, I believe that much of this has to do with the treatment objectives.

The rationale for stent-graft therapy is that covering the primary fenestration markedly decreases false lumen inflow, allowing the false lumen to passively decompress. We have found that perfusion of the mesenteric vessels, lower extremities, and renal branches are almost always restored via this technique once we reestablish true lumen flow, and it is exceedingly rare that we have to stent the branch vessels. In addition, the use of these stent grafts promotes false lumen thrombosis and in the region of the treatment may promote aortic remodeling. In contrast, aortic flap fenestration allows flow through a widened fenestration and equalization through the 2 lumens, which may increase the likelihood of static compression, at least in our experience.

How many arteries in your series required flap fenestration in addition to branch stenting, and were the outcomes different in those patients?

Dr Patel. Eric, again, you are correct in that by excluding false lumen flow with TEVAR, you may resolve the associated static obstruction by decompressing the false lumen. I at present do not have the number of arteries that required branch vessel stents in our cohort, but I can tell you that in our analysis, we did find that 43 of the 69 patients required branch vessel stents. We do agree that the point you raise is an important one, and we will have to construct that analysis to allow for a suitable comparison of both TEVAR and this approach.

Dr Roselli. I have one last question. It was a little disconcerting to us that in this large landmark series only 15 of the 69 patients were available at 2 years for, presumably, imaging studies, that is, in your second analysis in which you looked at freedom from reoperation and rupture. We share your view that once a patient has a dissection, he/she should become your patient for life, and all of the procedures that are performed should be done in the context of anticipating a later repair. You described 5 early ruptures and 14 patients with late rupture or reoperation, for a rate of more than $20 \%$. Do you think that the rate of significant growth of these aortas was even higher and that some of these patients were not deemed operative candidates? Also in this subgroup of patients, did you look to see if there were any other factors such as an initial aortic diameter of more than $4 \mathrm{~cm}$ or a false lumen diameter more than $22 \mathrm{~mm}$, and if so, should those patients have been treated with stent grafting in addition to fenestration and branch grafting?

Dr Patel. You are correct in stating a major limitation of our results. I think the point that we would like to make is that when we undertook this analysis, at the time when this procedure was really started, there was no ability to provide thoracic endografting for patients with acute type B dissection. The goal of the therapy when it was first started was to restore the branch vessel perfusion and perhaps restore the survival curve toward that seen with uncomplicated dissection.

You are absolutely right that the limitations of the article are such that we do not have complete imaging follow-up in this cohort. What we did find when we accounted for all of this was that the survival analysis suggested that the mean time to open repair or rupture was 79 months. We did not specifically look at aortic or false lumen diameters in this study. Whether the results we show are good or not, I am not sure, but we do believe that they are better than the results for open surgical series that have been reported and, as well, medical therapy for type B dissection presenting with ischemia. We therefore believe that the report we have proposed should be considered a better benchmark study for evaluation of newer therapies, such as TEVAR.

At our institution, we wholeheartedly believe in the thoracic endovascular approach in this setting, and I think there are certain advantages for TEVAR that we suspect are likely not present with the fenestration and stenting approach. However, as we move forward and more and more groups describe outcomes with endovascular repair for ischemic type $\mathrm{B}$ dissections, I think rather than comparing them with open repair, which has a known dismal prognosis, this report would probably be a more suitable comparison.

D. Craig Miller, MD (Stanford, Calif). Be careful what you wish for, Dr Patel, because the data are already out there. I wasn't going to get up until I heard you say that you use these results as a benchmark for thoracic aortic stent-grafting. I am sorry, but this is very old flap fenestration and a true lumen stenting approach can't compete. We explored "fen-stent" for complications of acute and chronic aortic dissection in the late 1980s and early 1990s but abandoned it for the most part when we started thoracic aortic stent-grafting in 1992, except when used as an adjunct after stent grafting.

An article published in 1999 with our colleagues at Mie University, Japan, included only 29 patients, certainly not a big number, but as Eric just said, let's carefully define the substrate we are talking about. These were very sick people with complicated acute type $\mathrm{B}$ dissections who were malperfused and basically dying in front of us. Our initial goal was simply patient salvage. There were some early deaths; we got caught, just like you have in Michigan, by trying even though irreversible end-organ damage had already occurred, or something Dr Shumway likened to "doing warm autopsies." We try to avoid this pitfall, but it is nearly impossible to know who is salvageable and who is not with certainty. Now, just including patients with Stanford complicated acute type B aortic dissection, we have 16 who underwent emergency thoracic aortic stent-grafting who have been followed for 5 years; follow-up completeness was $100 \%$. After the initial $25+$ or $-11 \%$ early mortality, there were no additional deaths. The 5-year actuarial survival estimate was $73+$ or $-11 \%$ (Verhoye JP, Miller DC, Sze D, Dake MD, Mitchell RS. Complicated acute type B aortic dissection: midterm results of emergency endovascular stent-grafting. J Thorac Cardiovasc Surg. 2008;136:424-30). Therefore, I submit this is the first-generation stent-graft benchmark you were referring to for comparison, not your results with "fen-stent." Flap fenestration and true lumen stenting for static obstruction are valuable adjuncts after stent grafting but cannot compete as a primary first line of therapy for acute aortic dissection today. 
Second, we have to define what we are trying to do. In your conclusion slide you listed rupture and death, and you said both are bad. Well, yes, death is usually pretty bad, but needing a late open operation is not necessarily bad. Maybe that should be part of our overall strategic goal, that is, do something quickly such as a stent-graft to ameliorate the life-threatening lower-body malperfusion, resuscitate the patients, and get them into better condition when an open thoracic or thoracoabdominal aortic operation under more favorable conditions might proffer the optimal likelihood of long-term survival. I don't have any questions; I am just issuing some words of caution.

Dr Patel. Just for the record, I will not compare myself with you. But I do suggest that we agree that endovascular repair for acute type B dissection is really here to stay, and we fully believe in it. We have a different approach at Michigan. We suggest that because of the unknown late results, we tend to perform thoracic endografting in older patients. However, in younger patients, we have been aggressive with fenestration and stenting. If they do require aorta repair for degeneration down the road, we do know from our series and others that elective open repair is associated with acceptable early and late results. In essence what we are doing with fenestration and stenting in younger patients is exactly what you proposed, and that is converting a patient who is dying in front of you into a more elective situation in which he/she is more salvageable.

Bruce W. Lytle, MD (Cleveland, Ohio). If I understand you correctly, however, today you would not choose to do this procedure. Or if I misunderstood you and you would perform this procedure rather than stenting, who would you do it for?

Dr Patel. We do still do this procedure. As I said, for patients who are younger, we do not know the long-term results of TEVAR in this setting. At our institution, if a younger patient presents with acute type $\mathrm{B}$ dissection with malperfusion, then we will often restore the branch vessel perfusion with fenestration and stenting. If the aorta subsequently degenerates, the patient will then often receive open therapy. If the patient is older, then we are more aggressive with performing an endograft approach to treat the malperfusion syndrome. 